\title{
Are sleeping site ecology and season linked to intestinal helminth prevalence and diversity in two sympatric, nocturnal and arboreal primate hosts (Lepilemur edwardsi and Avahi occidentalis)?
}

May Hokan 1,2, Elke Zimmermann², Ute Radespiel ${ }^{2}$, Bertrand Andriatsitohaina ${ }^{3}$, Solofonirina Rasoloharijaona ${ }^{3}$ and Christina Strube ${ }^{1 *}$ (D)

\begin{abstract}
Background: Various factors, such as climate, body size and sociality are often linked to parasitism. This constrains the identification of other determinants driving parasite infections. Here, we investigate for the first time intestinal parasites in two sympatric arboreal primate species, which share similar activity patterns, feeding ecology, body size and sociality, and cope with the same climate conditions, but differ in sleeping site ecology: the Milne-Edward's sportive lemur (Lepilemur edwardsi) and the Western woolly lemur (Avahi occidentalis). Comparison of these two species aimed to test whether differences in sleeping sites are related to differences in parasite infection patterns. Additionally, gender and seasonal factors were taken into account. Animals were radio-collared to record their sleeping site dynamics and to collect fecal samples to assess intestinal parasitism during both the dry and the rainy season.

Results: Only low parasite diversity was detected, which is attributable to the strict arboreal lifestyle of these lemurs, limiting their contact with infective parasite stages. L. edwardsi, which sleeps in tree holes and repeatedly uses the same sleeping site, excreted eggs of strongyle and oxyurid nematodes, whereby strongyles always occurred in coinfection with oxyurids. In contrast, A. occidentalis, which sleeps on open branches and frequently changes sleeping sites, only excreted eggs of strongyle nematodes. This difference can be attributed to a potential favorable environment presented by tree holes for infective stages, facilitating parasitic transmission. Additionally, Strongylida in A. occidentalis were only observed in the rainy season, suggesting an arrested development during the dry season in the nematodes' life cycle. Males and females of both lemur species showed the same frequency of parasitism. No differences in body mass of infected and non-infected individuals were observed, indicating that the animals' body condition remains unaffected by the detected gastrointestinal parasites.
\end{abstract}

Conclusions: The comparison of two primate hosts with a very similar lifestyle suggests an influence of the sleeping site ecology on intestinal parasites. In A. occidentalis there was a clear seasonal difference in strongyle egg excretion. These results improve our understanding of the parasite ecology in these endangered primate species, which may be critical in the light of species conservation.

Keywords: Helminths, Milne-Edward's sportive lemur, Western woolly lemur, Strongylida, Oxyurida, Arboreality, Seasonality, Sleeping site ecology

\footnotetext{
*Correspondence: christina.strube@tiho-hannover.de

${ }^{1}$ Institute for Parasitology, University of Veterinary Medicine Hannover, Buenteweg 17, 30559 Hannover, Germany

Full list of author information is available at the end of the article
} 


\section{Background}

Parasites can impact animal populations by reducing their host's condition [1], susceptibility to predation [2] or reproductive potential [3] and therefore fitness. Although intestinal parasites often act as commensals, they may become pathogenic in immunocompromised hosts [4]. Furthermore, when the animal is subject to chronic stress, for example through anthropogenic impact or temperature variations, e.g. related to climate change [5], parasite virulence can be increased [6, 7]. Parasites may also act as stressors themselves and facilitate coinfections with other pathogens [8]. Therefore, studies on patterns of parasitism in wild populations are needed, especially in host species that are increasingly endangered by anthropogenic threats.

Patterns of parasitic infections may be influenced by the host's ecology [9]. Along with diet, group size, density, ranging behavior and grooming, sleeping site choice may influence parasite load [10-12]. A previous study on primates by Hausfater and Meade [13] has postulated that sleeping site ecology may have a direct influence on parasite infection: yellow baboons (Papio cynocephalus) appear to avoid potential infection through their own fecal emission by regularly rotating their sleeping sites. However, the results of a more recent study on baboons in the same area found intervals of vacancy of the sites to be too short to reduce the risk of sharing parasites [14]. The selection of a sleeping site in Capuchin Monkeys (Cebus apella nigritus) is mainly influenced by the degree of safety it provides by reducing accessibility for predators [15]. Tamarins (Leontopithecus rosalia), for example, use tree cavities, which are big enough to permit their entry but not that of predators [16].

Sleeping sites, such as tree holes, can also provide shelter from unfavorable weather conditions so that inhabitants spend less energy on thermoregulation [17]. Another benefit of sleeping in tree holes is the decreased exposure to vectors leading to reduced rates of mosquito bites and thus to a lower infection risk of transmitted diseases such as malaria [18].

Using tree holes as sleeping sites also bears some disadvantages: the usage of shelters by multiple individuals can lead to increased parasite transfer $[19,20]$. Also, tree holes are limited compared to open sleeping sites, leading to a competition for such sites and to a higher rate of reutilization, which in turn leads to higher parasite infection rates $[21,22]$. Finally, a higher site fidelity, which can result from a preference for rare high quality sites [14] or from smaller home range sizes [23], may to lead to increased infection rates because of nest contamination. Another ecological trait worth mentioning in relation with parasitic infections is arboreality. In arboreal species, water- and soil-borne parasitic infection rates were found to be lower than in terrestrial species [24]. Purplefaced langurs (Semnopithecus vetulus) for instance avoid contaminated soil and water due to their arboreal habits, protecting them from acquiring Cryptosporidium sp. [25] and several arboreal mammal species in French Guinea show significantly lower prevalences of Toxoplasma gondii [26].

Environmental factors, such as temperature and rainfall, may also influence parasite occurrence. For example, humidity favors survival and hatching of helminth eggs, which may lead to an increase of parasite load in the rainy season $[27,28]$. Nevertheless, in some cases a lower parasite richness is observed in rainy season due to heavy rainfalls which can have "wash-out" effects on free living stages of nematodes decreasing fecal contamination [29].

Furthermore, sex differences in intestinal parasite infections have been documented, as the prevalence and infection intensity is occasionally reported to be higher in males than females [30-32]. This could be due to the immunosuppressive effect of testosterone and/or to higher exposure to parasites due to sex-specific behavior, such as aggression, foraging and grouping [33, 34]. However, prevalence of some parasite species may also be higher in females [35] and other studies showed no sex differences [36]. Hence, it is important to explore the possible influence of host sex and season in studies on parasite load in wildlife.

Other factors linked to parasitic infections in wild hosts are body size, group size, population density, sociality, feeding ecology and habitat [9-12]. Studies on the influence of sleeping sites on parasite infections in primates are so far limited $[13,18,37,38]$ and challenging due to the interaction of multiple factors. Thus, to assess the influence of a single factor, such as sleeping site ecology, the other elements need to be controlled. This can be achieved by studying two host species sharing similar influential factors like activity patterns, feeding ecology, body size, sociality and habitat. Here we investigated infection patterns with intestinal parasites in a wild population of two endangered Malagasy primates, the MilneEdward's sportive lemur (Lepilemur edwardsi) and the Western woolly lemur (Avahi occidentalis). These nocturnal lemurs live in northwestern Madagascar with a home range of 1 ha and an estimated density of 60 individuals/ $\mathrm{km}^{2}$ for L. edwardsi $[39,40]$ and a home range of 1.96 ha and a density of 67 individuals $/ \mathrm{km}^{2}$ for A. occidentalis [40-42]. Both species are pair-living, folivorous and have a similar body size of approximately $900 \mathrm{~g}$ [43-45] but differ in their sleeping site ecology. Sportive lemurs sleep in tree holes and individuals show high sleeping-site fidelity, whereas woolly lemurs sleep on open branches and shift their sleeping sites frequently $[46,47]$. Thus, we aimed to examine the influence of sleeping site ecology, 
seasonality and sex on intestinal parasite infection patterns in two lemur hosts with the same habitat, feeding ecology, density, activity, sociality and body size. We hypothesize that $L$. edwardsi shows a higher prevalence because they frequently revisit the same tree holes, facilitating transmission of infective parasite stages. We also expect a general influence of season with a higher prevalence during the rainy season. Additionally, if sex affects the infection status, we expect males of both species to excrete more eggs than females. Finally, we take into account the body mass of the hosts as an indicator for the hosts' body condition, to assess whether the presence of endoparasites compromises animals' health $[1,4,48]$.

\section{Methods}

\section{Study site}

The study was conducted in the Jardin Botanique A (JBA), a 30.6 ha forest parcel located at $16^{\circ} 19^{\prime} \mathrm{S}, 46^{\circ}$ $48^{\prime} \mathrm{E}$ in the Ankarafantsika National Park in northwestern Madagascar. The park contains dry deciduous forest and is subject to pronounced seasonality, with a dry season from May to October and a hot, rainy season from November to April (Fig. 1).

\section{Animal hosts}

Lemur capturing included a total of 26 individuals of $L$. edwardsi, 15 of which were recaptured at least once during the study, and 22 individuals of $A$. occidentalis, seven of which were recaptured. L. edwardsi was caught directly

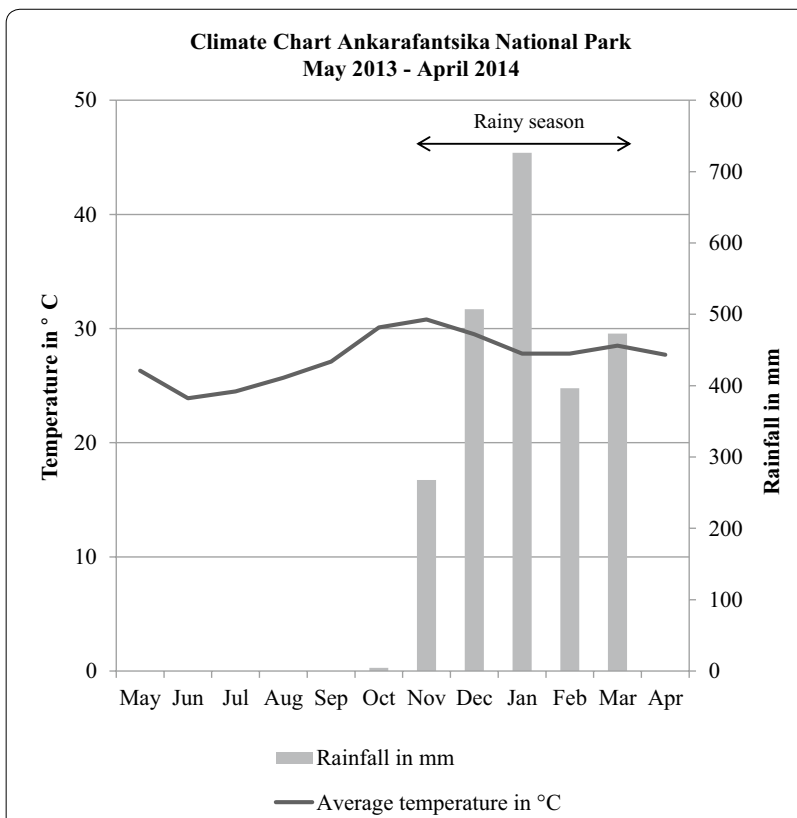

Fig. 1 Temperature and rainfall in the Ankarafantsika National Park during the sampling year in tree holes before immobilization with a combination of ketamine (Ketanest ${ }^{\circledR}$ Pfizer Deutschland $\mathrm{GmbH}$, Berlin, Germany, $25 \mathrm{mg} / \mathrm{ml}$ ) and xylazine (Rompun ${ }^{\circledR}$, Bayer AG, Leverkusen, Germany, $20 \mathrm{mg} / \mathrm{ml}$ ) for collaring. $A$. occidentalis were remotely immobilized with the same drug mixture by using a blowpipe and $1 \mathrm{ml}$ cold air pressure darts $\left(\right.$ Telinject $\left.{ }^{\circledR}\right)$. Dosages based on estimated body weights were $10 \mathrm{mg} / \mathrm{kg}$ ketamine and $0.5 \mathrm{mg} / \mathrm{kg}$ xylazine. During immobilization, a total of 13 individuals of L. edwardsi were radio-collared and nine individuals of A. occidentalis were equipped with a radio-transmitter backpack to avoid impairment of their natural marking behavior with throat glands [49]. All radio-transmitters were TW-3 tags (Biotrack, UK). The tagged individuals were chosen randomly. Additionally, all animals were microchipped (ID100 Microtransponder, Trovan ${ }^{\circledR}$ ), sexed and weighed (5 kg-balance, AEG). All procedures were approved by the Ministère de l'Environnement, de l'Ecologie et des Forêts and Madagascar National Parks (MNP) and necessary research permits were obtained from the competent Malagasy authorities (License $\mathrm{N}^{\circ}$ 167/13/MEF/SG/DGF/DCB.SAP/SCB obtained on the 13th of July 2013 and $\mathrm{N}^{\circ} 072 / 14$ obtained on the 12th of March 2014).

\section{Sleeping sites}

Sleeping sites were determined during two periods, from July to October 2013 representing the dry season as well as from March to May 2014 representing the rainy season. Radio-collared animals were located daily in the morning and their daytime sleeping site was marked with a numbered flag. Additionally, the GPS coordinates of the tree and the sleeping site type (tree hole or branch) were noted. The number of daytime sleeping sites used was determined for each individual (Additional file 1) and the mean number of days spent in one sleeping site was calculated. The latter data was used to compare the frequency of sleeping site rotation of $L$. edwardsi and $A$. occidentalis using a Mann-Whitney U Test (IBM SPSS Statistics, version 23).

\section{Sample collection}

Throughout two sampling periods (July-October 2013 and March-May 2014), 86 fecal samples from L. edwardsi (43 from the dry and 43 from the rainy season) and 74 samples from $A$. occidentalis (33 from the dry and 41 from the rainy season) were collected (Table 1, Additional files 2 and 3). During animal anesthesia, samples could be collected directly from the animal. However, from most specimens fecal samples were gained non-invasively by collection from the ground during nocturnal focal animal observations. A total of 111 samples were obtained from tagged and 49 samples from untagged animals. The firm, 
Table 1 Sample size and the number of sampled individuals in square brackets per season and per species

\begin{tabular}{lll}
\hline Host species & Dry season & Rainy season \\
\hline L. edwardsi & $43[23]$ & $43[19]$ \\
A. occidentalis & $33[18]$ & $41[16]$ \\
\hline
\end{tabular}

small droppings were collected as a whole, labeled individually and stored in $90 \%$ ethanol. In total, samples from 28 individual L. edwardsi and 29 individual A. occidentalis were obtained, which approximately represent the whole population present in JBA according to the densities reported by Ganzhorn [41] and Warren and Crompton [40] matching personal observations.

\section{Fecal flotation and identification of parasitic stages}

All fecal samples were processed by the flotation method using saturated sodium chloride $(\mathrm{NaCl}$, specific gravity 1.2) as flotation solution. In brief, feces were weighed, grind in a mortar and transferred to a $15 \mathrm{ml}$ centrifuge tube. Two-thirds of the tube were filled with distilled water. The fecal content was homogenized by shaking and centrifuged at $800 \mathrm{~g}$ for $10 \mathrm{~min}$. After centrifugation, the supernatant was removed and pelleted feces were poured through a tea strainer (mesh size $0.5 \mathrm{~mm}$ ) into a $50 \mathrm{ml}$ tube. Feces remaining in the tea strainer were washed with saturated $\mathrm{NaCl}$ until the $50 \mathrm{ml}$ tube was full. A microscope cover slip covering the entire opening was placed on top of the tube and transferred to a microscope slide after $30 \mathrm{~min}$. For each sample, the slide was scanned and parasite eggs were counted using the $10 \times$ objective. The $40 \times$ objective was used to identify parasites based on morphological parameters using descriptions from Irwin and Raharison [50]. Parasites were photographed with an Olympus CAMEDIA C-5050 Zoom digital camera, then visualized and measured with the cell ${ }^{\wedge} \mathrm{B}$ Image Acquisition Software (version 3.1; Olympus Soft Imaging Solutions).

\section{Statistical analyses of parasites}

First, the overall prevalence of each parasite type for $L$. edwardsi and A. occidentalis was analyzed. For this purpose, each individual entered the calculation only once per season and an animal was considered positive, if at least one of its samples from that season was positive. For subsequent analyses, the information content of multiple samples per individual and season was included. To assess the influence of host species, sex and season on the probability of being infected with a certain egg type, a generalized linear mixed model (GLMM) with binomial error structure and logit link function was implemented. The models contained the variables "species" (L. edwardsi, A. occidentalis), "sex" (male, female) and "season" (dry, rainy) as fixed factors. Animal ID was included as a random factor to account for the fact that many individuals $(56.1 \%)$ contributed more than one sample. Full models were tested containing all factors, followed by evaluation of the significance of each factor. The exponential function was used to calculate the extent of difference between two groups when a factor was significant. Except when examining the factor host species, all analyses were conducted separately for $L$. edwardsi and $A$. occidentalis and for each parasite morphotype, in order to infer whether the observed effect is only present in one or in both host species. In L. edwardsi, the number of tree holes used by each radio-collared individual was tested additionally. In $A$. occidentalis, the factor season was not evaluated statistically because no intestinal helminths were ever found in the dry season. The analyses were performed in R v.3.2.2 [51] using the package lme4 [52].

Fecal egg counts (FEC) as a measurement of infection intensity were not analyzed further, since the observed oxyurid parasites do not excrete their eggs in the intestinal lumen, but deposit them on the perianal region, while egg excretion of strongyle nematodes is not necessarily correlated with parasite intensity.

As an indicator for the host's condition, we examined the host's body mass [48]. Using a Mann-Whitney U Test (IBM SPSS Statistics, version 23), it was tested whether there was a difference in body mass between individuals excreting helminth eggs and those who did not. Only body mass data from adult individuals and from the rainy season was taken into account, as during this season no pregnant females are present, and there is no restriction in food supply.

\section{Results}

\section{Sleeping sites}

Sleeping sites of 13 individuals of $L$. edwardsi and 9 individuals of $A$. occidentalis were determined over a total of 130 days. Due to losses caused by predation or animals that could not be located on some days, sleeping sites were determined at an average of 98 days (min: 36, max: 129 days) for $L$. edwardsi and 68 days (min: 24, max: 119 days) for $A$. occidentalis (Additional file 1).

Sleeping sites of $L$. edwardsi $(\mathrm{N}=13)$ were tree holes in $100 \%$ of the observations and an individual sleeping site was used for a mean of 25 days (range 1-107 days, Additional files 4 and 5). They slept solitarily, in pairs or in a family group. A. occidentalis $(\mathrm{N}=9)$ used the same sleeping site for a mean of 4 days (range 1-28 days, Additional files 6 and 7). Woolly lemurs always slept in pairs 
or families huddled together on branches or tree forks. The individual average usage frequency of a sleeping site was significantly different between the two lemur species (Mann-Whitney $U=0, n_{1}=13, n_{2}=9, p=0.0002$ ).

\section{Parasite diversity and prevalence}

Both lemur species excreted helminth eggs, but no protozoal stages were detected. Fecal samples of L. edwardsi contained oxyurid (Lemuricola spp.) and strongyle eggs (Figs. 2 and 3). Strongyle eggs were only recovered from individuals, which were also infected with Lemuricola spp. (in six samples), whereas 30 samples (34.9\%) were positive for Lemuricola spp. only. The asymmetrical, thin-walled Lemuricola eggs were all similar in shape and size, with a mean length of $71.4 \mu \mathrm{m}$ (SD $5 \mu \mathrm{m})$ and a mean width of $32.3 \mu \mathrm{m}$ (SD $4 \mu \mathrm{m})(\mathrm{N}=50)$ and contained an embryo (Fig. 2). Strongyle eggs from L. edwardsi measured $71.1 \mu \mathrm{m}$ (SD $5 \mu \mathrm{m})$ by $43.8 \mu \mathrm{m}$ (SD $4 \mu \mathrm{m})$ in width $(\mathrm{N}=6)$ and contained a morula or larva (Fig. 3$)$. Fecal samples of $A$. occidentalis contained only strongyle eggs, resembling those from $L$. edwardsi and measuring $69.9 \mu \mathrm{m}(\mathrm{SD} 4 \mu \mathrm{m})$ in length by $43.0 \mu \mathrm{m}(\mathrm{SD} 3 \mu \mathrm{m})$ in width $(\mathrm{N}=40)$.

The overall prevalence in $L$. edwardsi was $64.3 \%$ ( $\mathrm{N}=28$ individuals) for Lemuricola spp. and $21.4 \%$ $(\mathrm{N}=28$ individuals) for Strongylida. Eggs were shed in both seasons (Table 2). For A. occidentalis, the overall Strongylida prevalence was $20.7 \%$ ( $N=29$ individuals), but egg shedding was only observed during the rainy season (March-May 2014).

Effect of host species, sex and season on parasite infection A statistically significant effect of host species on parasite infection status was observed. According to the

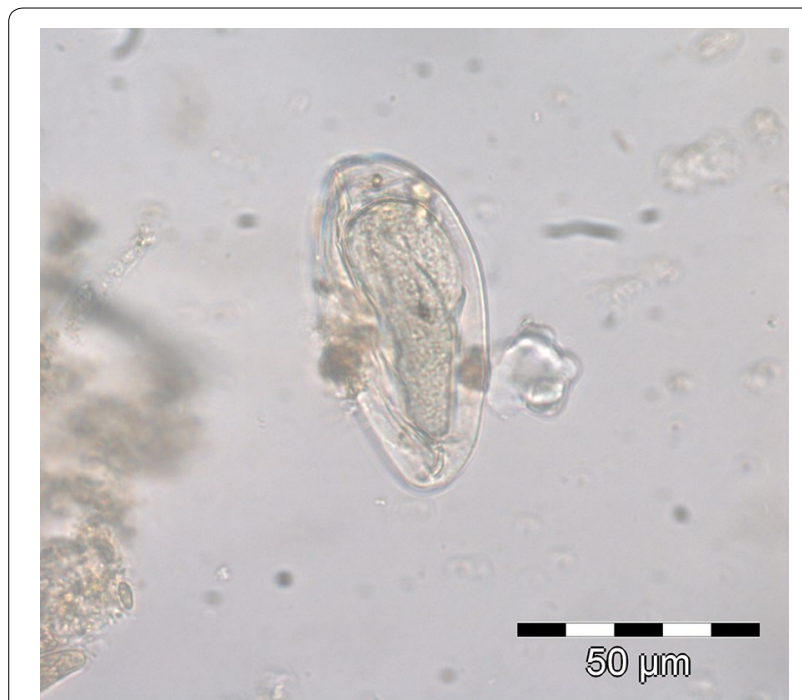

Fig. 2 Oxyurid egg (Lemuricola spp.) of L. edwardsi

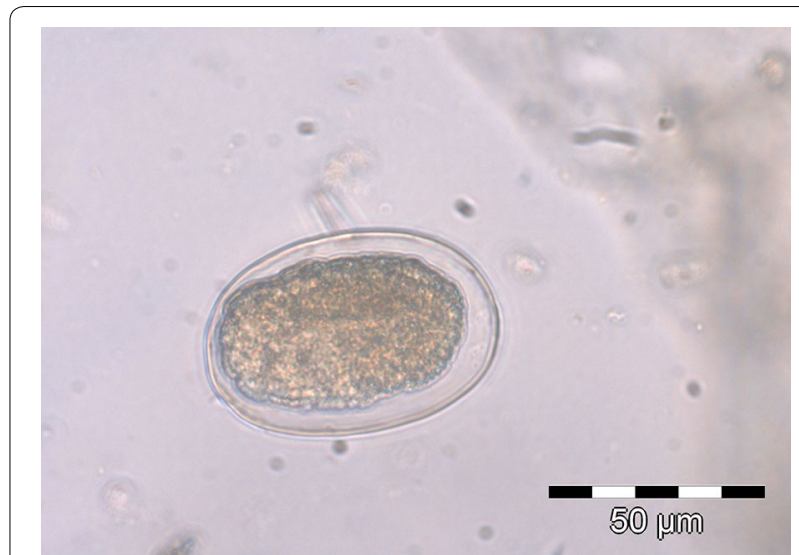

Fig. 3 Strongyle egg of L. edwardsi

exponential function, the probability of shedding parasite eggs was three times higher for L. edwardsi than for A. occidentalis (CI 1.3-8.6, Table 3). In addition, season clearly had an influence on strongyle infections in $A$. occidentalis, showing $0.0 \%$ prevalence in the dry season, but $37.5 \%$ prevalence in the rainy season (Table 2). However, this was not the case for $L$. edwardsi, as likelihood of infection was not significantly affected by season for neither parasite morphotype (Table 3). The number of tree holes used as sleeping sites by $L$. edwardsi did not significantly affect their likelihood of infection with either parasite. Finally, neither host species showed a significant effect of sex on parasite infection; $37.2 \%$ of males and $44.2 \%$ females of $L$. edwardsi as well as $75.0 \%$ of males and $69.2 \%$ females of $A$. occidentalis were tested positive.

\section{Parasites and body mass}

In both host species body mass of individuals shedding eggs was not significantly different from those who did not excrete eggs (L. edwardsi: Mann-Whitney $U=28.5$, $\mathrm{n}_{1}=10, \mathrm{n}_{2}=6 p=0.88 ;$ A. occidentalis Mann-Whitney $U=9, \mathrm{n}_{1}=8, \mathrm{n}_{2}=5, p=0.13$ ) (Additional file 8).

Table 2 Number of infected individuals out of the number of sampled $L$. edwardsi or $A$. occidental in each season with seasonal prevalences in brackets

\begin{tabular}{llllll}
\hline Host species & Dry season & & & \multicolumn{2}{l}{ Rainy season } \\
\cline { 2 - 3 } & $\begin{array}{l}\text { Lemuricola } \\
\text { spp. }\end{array}$ & Strongyles & & $\begin{array}{l}\text { Lemuricola } \\
\text { spp. }\end{array}$ & Strongyles \\
\hline L. edwardsi & $11 / 23(47.8 \%)$ & $2 / 23(8.7 \%)$ & $11 / 19(57.9 \%)$ & $4 / 19(21.1 \%)$ \\
A. occidentalis & $0 / 18(0.0 \%)$ & $0 / 18(0.0 \%)$ & $0 / 16(0.0 \%)$ & $6 / 16(37.5 \%)$
\end{tabular}


Table 3 Results of GLMMs testing the influence of animal species, sex, season and number of used tree holes on helminth prevalence

\begin{tabular}{|c|c|c|c|c|c|}
\hline Measure & Term & Estimate & Standard error & $\mathbf{z}$ & $p$ value \\
\hline \multirow[t]{2}{*}{ Overall prevalence } & Intercept & -1.47 & 0.39 & -3.78 & $<0.001^{*}$ \\
\hline & Species & 1.08 & 0.45 & 2.43 & $0.015^{*}$ \\
\hline \multirow[t]{4}{*}{ Lemuricola spp. prevalence in L. edwardsi } & Intercept & 0.98 & 0.72 & 1.35 & 0.178 \\
\hline & Sex & -0.44 & 0.51 & -0.85 & 0.395 \\
\hline & Season & -0.30 & 0.57 & -0.57 & 0.572 \\
\hline & Tree holes & -0.45 & 0.29 & -0.15 & 0.125 \\
\hline \multirow[t]{4}{*}{ Strongylida prevalence in L. edwardsi } & Intercept & -2.68 & 1.15 & -2.34 & $0.019^{*}$ \\
\hline & Sex & -1.94 & 1.20 & -1.62 & 0.106 \\
\hline & Season & -0.57 & 1.95 & -0.60 & 0.106 \\
\hline & Tree holes & 0.57 & 0.47 & 1.20 & 0.229 \\
\hline \multirow[t]{2}{*}{ Strongylida prevalence in A. occidentalis } & Intercept & -4.83 & 4.34 & -1.11 & 0.266 \\
\hline & Sex & 0.87 & 1.90 & 0.46 & 0.649 \\
\hline
\end{tabular}

* Significant $p$ values $(\leq 0.05)$

\section{Discussion}

Parasite transmission modes and the influence of ecological factors on infection patterns are still unclear in many ecosystems. In this study, intestinal parasite infection patterns in L. edwardsi and A. occidentalis, which occur in sympatry in Ankarafantsika National Park in north-western Madagascar, were examined to compare their association with host traits such as sleeping site ecology and sex, as well as with environmental factors (season). In general, both species harbored a low diversity of intestinal helminths and no protozoal stages were detected. Lepilemur edwardsi excreted strongyle as well as oxyurid eggs, a result comparable to the findings of previous studies on Lepilemur spp. [53-56]. By contrast, A. occidentalis excreted exclusively strongyle eggs, which is also consistent with findings of previous studies $[57,58]$. Although the strongyle eggs found in $A$. occidentalis resemble those found in $L$. edwardsi, it is quite possible that they belong to different parasite species. Molecular analysis would be needed to clarify this matter. Neither host species showed a difference in body mass between individuals excreting these helminth eggs and those who did not. If not resulting from low statistical power due to the small sample size, this might be an indication that the animals' health is not compromised by the presence of the observed strongyle and oxyurid nematodes. Furthermore, the intensity of infection may be too low to exert any adverse effects. Unfortunately, determination of reliable infection intensity was not possible in our study, since egg excretion of strongyle nematodes is not necessarily correlated with infection intensity and egg excretion of oxyurid nematodes occurs in the perianal region rather than the intestinal lumen. Thus, the determined percentage of Lemuricola spp. infections might not reflect the true but rather an underestimated prevalence.

Beside strongyles, only one other type of intestinal helminth, the tapeworm Bertiella lemuriformis, was previously noted in Avahi spp. [59]. This noticeably low parasite species richness may have several ecological reasons as discussed below, but might also be a consequence of the very limited number of studies existing on parasites in Lepilemur and Avahi species. Even though the present study may be hampered by the moderate sample numbers of $28 \mathrm{~L}$. edwardsi and 29 A. occidentalis specimens, these individuals nearly represent the whole Lepilemur and Avahi population of the 30.6 ha study site $[40,41]$, as both populations have suffered a strong decline due to poaching during the last years. Therefore, if other parasite infections are present in this population, they should be visible in this almost complete population sample.

One ecological mechanism leading to reduced parasite species richness may be the strict arboreal lifestyle of these primates, who leap from tree to tree avoiding ground contact [60]. As many parasites develop their infective stage in the environment, transmission is reduced when contact with the contaminated forest floor is limited. This has also been observed in Verreaux's sifaka (Propithecus verreauxi), another arboreal lemur species [61, 62]. Remarkably, it has been demonstrated that threatened host taxa harbor fewer parasite species because of the host's lower population size and range area [63]. As both of the studied lemur populations probably underwent population bottlenecks before this study, the low parasite richness may also result from the direct loss of parasite species, meaning that parasites can "fade 
out" and they can go extinct long before their host [64]. The folivorous diet of $L$. edwardsi and A. occidentalis, may also explain the low parasite species richness found in this study as it prevents infection from parasite genera using invertebrates as intermediate hosts. Another possible explanation for the low parasite species richness may be the relatively small group size as parasite transmission may increase with the number of animals in a group [12]. Furthermore, a monogamous lifestyle limits the number of sexual and grooming partners, reducing chances of contamination with parasites that are amongst others transmitted through direct contact, such as Lemuricola spp. Both aspects, small groups as well as monogamy apply to $A$. occidentalis and $L$. edwardsi, which were mainly observed sleeping in pairs in the present study, restricting close contact to multiple individuals.

One of the main objectives of this study was to test the influence of sleeping site ecology on endoparasite prevalence and species richness. As expected, L. edwardsi, which sleeps in tree holes, showed higher prevalence and parasite species richness than $A$. occidentalis, which sleeps on open branches. The population density and social organization of these primate species is similar, both species live in pairs or small groups and are monogamous, they share their habitat with identical climate conditions, have the same activity pattern and a similar feeding ecology, so that all these factors cannot explain the differences observed between the two species. The comparison of these hosts indicates that the specific sleeping site ecology of $L$. edwardsi may promote intestinal parasitism. The used tree holes are often frequented by two or three L. edwardsi individuals at a time, resulting in close physical contact between individuals. Oxyurid nematodes, a parasite group that was only found in L. edwardsi and not in A. occidentalis, attach their eggs to the host's perianal region. Thus, close physical contact may increase contamination of co-sleeping family members. Moreover, L. edwardsi individuals used their sleeping sites significantly longer than A. occidentalis (mean of 25 days vs. 4 days). A regularly re-visited, closed sleeping site presents a favorable environment for parasites with a direct life cycle, such as strongyle nematodes previously described in lemurs [50].

In contrast to $A$. occidentalis, strongyle parasites were observed in both seasons in $L$. edwardsi. This may be attributed to the favorable conditions for parasite development within tree holes, which facilitate year-round transmission of infective larvae. However, it has to be considered that despite the many ecological similarities observed between A. occidentalis and L. edwardsi, these two species belong to separate lemur families, the Indriidae and the Lepilemuridae, which have diverged 10 million years ago [65]. Coevolution of parasites with their host as well as loss of parasites over evolutionary time are important processes determining parasite assemblages [66]. Oxyurid nematodes have also been described in L. ruficadatus [67] and L. dorsalis [68], whereas to our knowledge, no oxyurid nematodes have been found in Avahi species. Therefore, the fact that oxyurid nematodes were only present in $L$. edwardsi might also be owed to the loss of this parasite during the evolution of A. occidentalis.

Even though the social behaviour of both species is similar, $L$. edwardsi is observed to engage more often in allogrooming than $A$. occidentalis [40]. Consequently, the higher parasitism in $L$. edwardsi could also be explained by its social interactions outside the sleeping holes. Thus, to verify the hypothesis that sleeping site ecology indeed affects endoparasitism, it would be necessary to analyze the effect of variation in this trait on parasite infection within the same species.

In the current study, the influence of the number of different sleeping sites (in this case tree holes) on infection status in $L$. edwardsi was tested, however, no impact of the re-use pattern of sleeping sites on infection status was observed. This is probably due to the low number of observed individuals in combination with a small variance in the number of used sleeping sites. Since it could not be determined how many individuals were sleeping together in a tree hole (except for few random nights), the influence of this factor on parasite prevalence and species diversity could not be analyzed. Further intraspecific studies on Lepilemur spp. or on other mammals with varying sleeping site dynamics are needed to fully understand the interaction between sleeping site ecology and parasitism. By comparing individuals of the same species one can exclude socio-behavioral and evolutionary differences.

Along with host's behavioral properties, seasonal differences in parasite prevalence have been studied and noted repeatedly in primates [27, 69]. As expected, our study revealed a higher prevalence in the rainy season in A. occidentalis. This may be attributed to increased temperature and humidity during the rainy season, favoring survival and development of parasite eggs as well as larval hatching. Nevertheless, it was remarkable that strongyle prevalence in A. occidentalis dropped to $0 \%$ in the dry season, compared to about $38 \%$ prevalence in the rainy season. This phenomenon may be explained by an arrested development of the strongyle parasites. When conditions for external larval development are unfavorable (dry or cold), nematode larvae may undergo hypobiosis, a temporary inhibition of development at a point of their life cycle in the gut mucosa of the host [70]. This ability has been described in numerous strongyle nematodes, such as Trichostrongylidae, 
Ancylostomatidae and Strongylidae [71]. Arrested development is often observed in cattle and sheep and usually occurs in winter in temperate regions or in summer in hot dry regions [72]. In tropical parts of the world, like Madagascar, arrested development during the dry season may be beneficial for the parasite, as humidity is low and temperatures are cooler, hampering larval development. However, no seasonal difference in Strongylida prevalence was found in $L$. edwardsi. They were present during both seasons and do not seem to have arrested their development, possibly as a consequence of the favorable surroundings offered by tree holes as mentioned above. The oxyurid nematodes in $L$. edwardsi appeared to be unaffected by weather as well, which can be explained by the fact that the infective stages live in close proximity to the host (in the fur at the perianal region) and are therefore less dependent on the environmental circumstances like high temperature and humidity.

Finally, the effect of sex on the likelihood of infection with intestinal parasites was analyzed. No sex differences were noted in both of the study species, which is in accordance with numerous other studies [12, 73, 74]. Factors sometimes linked to higher parasite prevalence in males are the immunosuppressive effects of higher testosterone levels in males, sexual dimorphism in body size as well as sex-specific behavior [33, 34]. When behavior changes with season, i.e. males are more active during the mating season, season-specific sex differences may be observed [75]. The absence of sex differences in the presented study may not be surprising, since $A$. occidentalis and $L$. edwardsi are sexually monomorphic with regard to body size and body mass $[44,46]$, and there might be only small differences in testosterone levels between males and females due to female dominance $[44,76,77]$.

\section{Conclusions}

The presented study compared two primate hosts, $L$. edwardsi and A. occidentalis, which have a very similar lifestyle, but differ in their choice of sleeping sites (tree holes vs. branches), using them as a model to assess the influence of sleeping sites on intestinal parasite prevalence and species richness. Species diversity of intestinal parasites found in both host species was low compared to other wild primates. This may be associated, inter alia, with the arboreal lifestyle of these lemurs, limiting their contact with infective parasite stages as feces fall to the ground. L. edwardsi showed a higher prevalence and diversity of endoparasitic helminths than $\mathrm{A}$. occidentalis, which might be due to the fact that this species sleeps in tree holes and shows high sleeping site fidelity, whereas $A$. occidentalis sleeps on open branches with a lower sleeping site fidelity, suggesting an influence of the sleeping site ecology on intestinal helminths. This should be verified by further intraspecific studies analyzing the influence of varying sleeping site dynamics on parasitism. Additionally, a seasonal difference in parasite infection was observed in A. occidentalis with strongyle egg excretion being observed solely during the rainy season. This may suggest an arrested development of strongyle nematodes harbored by A. occidentalis during the dry season. However, season did not seem to affect helminth infection in L. edwardsi. Overall, this study enhances the present knowledge of intestinal parasite communities and their determinants for nocturnal and arboreal primates.

\section{Additional files}

Additional file 1. Number of sleeping site observation days per month of each radio-collared individual.

Additional file 2. Number of individuals sampled at different frequencies (once to six times) during the dry and the rainy season.

Additional file 3. Individual sampling frequency in the dry and in the rainy season.

Additional file 4. Number of days each individual of L. edwardsi spent in one sleeping site.

Additional file 5. Map of the forest parcel JBA showing the location of the sleeping sites of L. edwardsi. Every symbol represents the sleeping site of an individual or couple.

Additional file 6. Number of days each individual of $A$. occidentalis spent in one sleeping site.

Additional file 7. Map of the forest parcel JBA showing the location of the sleeping sites of $A$. occidentalis. Every symbol represents the sleeping site of a couple or family group.

Additional file 8. Body mass and parasite egg excretion of individuals.

\section{Authors' contributions}

EZ initiated this study and guided the zoological part in Madagascar. EZ, CS and UR conceived and designed the study. $\mathrm{MH}$ and BA collected the data, $\mathrm{MH}$ performed laboratory work and drafted the manuscript. CS supervised the parasitological examinations. UR instructed statistical analyses of the data. All authors participated in data analysis and interpretation. All authors read and approved the final manuscript.

\section{Author details}

${ }^{1}$ Institute for Parasitology, University of Veterinary Medicine Hannover, Buenteweg 17, 30559 Hannover, Germany. ${ }^{2}$ Institute of Zoology, University of Veterinary Medicine Hannover, Buenteweg 17, 30559 Hannover, Germany. ${ }^{3}$ Département de Biologie Animale et Écologie, Faculté des Science, Université de Mahajanga, 401 Mahajanga, Madagascar.

\section{Acknowledgements}

We thank the Ministère de l'Environnement, de l'Ecologie et des Forêts and Madagascar National Parks for granting research permits. We are grateful to Romule Rakotondravony for continuous support in Madagascar and to Jhonny Kennedy for guide services, as well as Fayeggi Ambinini Anjara, Hannah Emde and Tina Kesselring for their assistance during field work and the Durrell Wildlife Preservation Trust for providing climate data of Ampijoroa. We also thank Andrea Springer for commenting on the manuscript and Sönke von den Berg for technical support. This work was supported by the German Academic Exchange Service (DAAD) and the German Society for Primatology (GfP).

\section{Competing interests}

The authors declare that they have no competing interests. 


\section{Availability of data and materials}

All data generated or analyzed during this study are included in this published article and its additional files.

\section{Consent for publication}

Not applicable.

\section{Ethics approval and consent to participate}

All procedures were approved by the Ministère de l'Environnement, de l'Ecologie et des Forêts and Madagascar National Parks (MNP), and necessary research permits were obtained from the Malagasy authorities (License $\mathrm{N}^{\circ}$ 167/13/MEF/SG/DGF/DCB.SAP/SCB obtained on the 13th of July 2013 and $N^{\circ} 072 / 14$ obtained on the 12 th of March 2014).

\section{Funding}

The German Academic Exchange Service (DAAD) funded travel expenses and field stay for data collection. The Gesellschaft für Primatologie (GfP) supported costs for material and Malagasy field assistants.

\section{Publisher's Note}

Springer Nature remains neutral with regard to jurisdictional claims in published maps and institutional affiliations.

Received: 8 January 2018 Accepted: 1 July 2018

Published online: 13 July 2018

\section{References}

1. Coop RL, Holmes PH. Nutrition and parasite interaction. Int J Parasitol. 1996;26:951-62

2. Hudson PJ, Dobson AP, Newborn D. Do parasites make prey vulnerable to predation? Red grouse and parasites. J Anim Ecol. 1992;61:681-92.

3. Hillegass MA, Waterman JM, Roth JD. Parasite removal increases reproductive success in a social African ground squirrel. Behav Ecol. 2010;21:696-700

4. Chapman CA, Wasserman MD, Gillespie TR, Speirs ML, Lawes MJ, Saj TL, Ziegler TE. Do food availability, parasitism, and stress have synergistic effects on red colobus populations living in forest fragments? Am J Phys Anthropol. 2006;131:525-34.

5. Patz JA, Graczyk TK, Geller N, Vittor AY. Effects of environmental change on emerging parasitic diseases. Am J Parasitol. 2000;30:1395-405.

6. Daszak P, Cunningham AA, Hyatt AD. Emerging infectious diseases of wild life - threats to biodiversity and human health. Science. 2000;287:443-9.

7. Junge RE, Barrett MA, Yoder AD. Effects of anthropogenic disturbance on indri (Indri indri) health in Madagascar. Am J Primatol. 2011;73:632-42.

8. Marcogliese DJ, Pietrock M. Combined effects of parasites and contaminants on animal health: parasites do matter. Trends Parasitol. 2011;27:123-30.

9. Nunn CL, Altizer S. Infectious diseases in primates: behavior, ecology, and evolution. 1st ed. Oxford: Oxford University Press; 2006.

10. Vitone ND, Altizer S, Nunn CL. Body size, diet and sociality influence the species richness of parasitic worms in anthropoid primates. Evol Ecol Res. 2004;6:183-9.

11. Altizer S, Nunn CL, Thrall PH, Gittleman JL, Antonovics J, Cunningham AA, Cunnningham AA, Dobson AP, Ezenwa V, Jones KE. Social organization and parasite risk in mammals: integrating theory and empirical studies. Annu Rev Ecol Evol Syst. 2003;34:517-47.

12. Clough D, Heistermann M, Kappeler PM. Host intrinsic determinants and potential consequences of parasite infection in free-ranging red-fronted lemurs (Eulemur fulvus rufus). Am J Phys Anthropol. 2010;142:441-52.

13. Hausfater $G$, Meade BJ. Alternation of sleeping groves by yellow baboons (Papio cynocephalus) as a strategy for parasite avoidance. Primates. 1982;23:287-97.

14. Markham AC, Alberts SC, Altmann J. Haven for the night: sleeping site selection in a wild primate. Behav Ecol. 2015;27:29-35.

15. Di Bitetti MS, Vidal EML, Baldovino MC, Benesovsky V. Sleeping site preferences in tufted capuchin monkeys (Cebus apella nigritus). Am J Primatol. 2000;50:257-74.
16. Coimbra-Filho AF Natural shelters of Leontopithecus rosalia and some ecological implications (Callitrichidae: Primates). In: Kleiman DG, editor. The biology and conservation of the Callitrichidae. Washington, DC: Smithsonian Institution Press; 1977. p. 79-89.

17. Anderson JR. Sleep, sleeping sites, and sleep-related activities: awakening to their significance. Am J Primatol. 1998;46:63-75.

18. Heymann EW. Sleeping habits of tamarins, Saguinus mystax and Saguinus fuscicollis (Mammalia; Primates; Callitrichidae), in north-eastern Peru. J Zool. 1995:237:211-26.

19. Kappeler PM, Cremer S, Nunn CL. Sociality and health: impacts of sociality on disease susceptibility and transmission in animal and human societies. Philos Trans R Soc B. 2015;370:20140116.

20. Zohdy S, Kemp AD, Durden LA, Wright PC, Jernvall J. Mapping the social network: tracking lice in a wild primate (Microcebus rufus) population to infer social contacts and vector potential. BMC Ecol. 2012;12:4.

21. Day RT, Elwood RW. Sleeping Site Selection by the Golden-handed Tamarin Saguinus midas midas: the role of predation risk, proximity to feeding sites, and territorial defence. Ethology. 1999;105:1035-51.

22. McGrew W, Tutin C, Collins D, File S. Intestinal parasites of sympatric Pan troglodytes and Papio spp. at two sites: Gombe (Tanzania) and Mt. Assirik (Senegal). Am J Primatol. 1989;17:147-55.

23. Lindenfors $P$, Nunn $C L$, Jones KE, Cunningham AA, Sechrest W, Gittleman $J$ L. Parasite species richness in carnivores: effects of host body mass, latitude, geographical range and population density. Glob Ecol Biogeogr. 2007;16:496-509.

24. Munene E, Otsyula M, Mbaabu DAN, Mutahi WT, Muriuki SMK, Muchemi GM. Helminth and protozoan gastrointestinal tract parasites in captive and wild-trapped African non-human primates. Vet Parasitol. 1998;78:195-201.

25. Ekanayake DK, Arulkanthan A, Horadagoda NU, Sanjeevani GKM, Kieft R, Gunatilake S, Dittus WPJ. Prevalence of Cryptosporidium and other enteric parasites among wild non-human primates in Polonnaruwa, Sri Lanka. Am J Trop Med Hyg. 2006;74:322-9.

26. de Thoisy B, Demar M, Aznar C, Carme B. Ecologic correlates of Toxoplasma gondii exposure in free-ranging neotropical mammals. J Wildl Dis. 2003;39:456-9.

27. Eckert KA, Hahn NE, Genz A, Kitchen DM, Stuart MD, Averbeck GA, Stromberg BE, Markowitz H. Coprological surveys of Alouatta pigra at two sites in Belize. Int J Primatol. 2006;27:227-38.

28. Banks D, Singh R, Barger I, Pratap B, Le Jambre L. Development and survival of infective larvae of Haemonchus contortus and Trichostrongylus colubriformis on pasture in a tropical environment. Int J Parasitol. 1990;20:155-60.

29. Poirotte C, Basset D, Willaume E, Makaba F, Kappeler PM, Charpentier MJE. Environmental and individual determinants of parasite richness across seasons in a free-ranging population of Mandrills (Mandrillus sphinx). Am J Phys Anthropol. 2016;159:442-56.

30. Lewis J, Twigg G. A study of the internal parasites of small rodents from woodland areas in Surrey. J Zool. 1972;166:61-77.

31. Evans RH. Baylisascaris procyonis (Nematoda: Ascaridae) in raccoons (Procyon lotor) in Orange County, California. Vector Borne Zoonotic Dis. 2001;1:239-42.

32. Bertolino S, Wauters LA, De Bruyn L, Canestri-Trotti G. Prevalence of coccidia parasites (Protozoa) in red squirrels (Sciurus vulgaris): effects of host phenotype and environmental factors. Oecologia. 2003;137:286-95.

33. Zuk M, McKean KA. Sex differences in parasite infections: patterns and processes. Int J Parasitol. 1996;26:1009-24.

34. Klein S. Hormonal and immunological mechanisms mediating sex differences in parasite infection. Parasite Immunol. 2004;26:247-64.

35. Maclntosh AJ, Hernandez A, Huffman M. Host age, sex, and reproductive seasonality affect nematode parasitism in wild Japanese macaques. Primates. 2010;51:353-64.

36. Radespiel U, Schaber K, Kessler SE, Schaarschmidt F, Strube C. Variations in the excretion patterns of helminth eggs in two sympatric mouse lemur species (Microcebus murinus and M. ravelobensis) in northwestern Madagascar. Parasitol Res. 2015;114:941-54.

37. Anderson JR, McGrew WC. Guinea baboons (Papio papio) at a sleeping site. Am J Primatol. 1984;6:1-14

38. Kowalewski M, Zunino GE. The parasite behavior hypothesis and the use of sleeping sites by black howler monkeys (Alouatta caraya) in a discontinuous forest. Neotrop Primates. 2005:13:22-6. 
39. Rasoloharijaona S, Randrianambinina B, Braune P, Zimmermann E. Loud calling, spacing, and cohesiveness in a nocturnal primate, the Milne Edwards'sportive lemur (Lepilemur edwardsi). Am J Phys Anthropol. 2006;129:591-600.

40. Warren RD, Crompton $\mathrm{RH}$. A comparative study of the ranging behaviour activity rhythms and sociality of Lepilemur edwardsi (Primates, Lepilemuridae) and Avahi occidentalis (Primates, Indriidae) at Ampijoroa, Madagascar. J Zool. 1997;243:397-415.

41. Ganzhorn JU. Food partitioning among Malagasy primates. Oecologia. 1988;75:436-50

42. Ramanankirahina R, Joly M, Scheumann M, Zimmermann E. The role of acoustic signaling for spacing and group coordination in a nocturnal, pair-living primate, the western woolly lemur (Avahi occidentalis). Am J Phys Anthropol. 2016;159:466-77.

43. Thalmann U. Food resource characteristics in two nocturnal lemurs with different social behavior: Avahi occidentalis and Lepilemur edwardsi. Int J Primatol. 2001;22:287-324.

44. Ramanankirahina $\mathrm{R}$, Joly M, Zimmermann E. Peaceful primates: affiliation, aggression, and the question of female dominance in a nocturnal pairliving lemur (Avahi occidentalis). Am J Primatol. 2011;73:1261-8.

45. Méndez-Cárdenas MG, Zimmermann E. Duetting—a mechanism to strengthen pair bonds in a dispersed pair-living primate (Lepilemur edwardsi)? Am J Phys Anthropol. 2009;139:523-32.

46. Rasoloharijaona S, Rakotosamimanana B, Randrianambinina B, Zimmermann E. Pair-specific usage of sleeping sites and their implications for social organization in a nocturnal Malagasy primate, the Milne Edwards' sportive lemur (Lepilemur edwardsi). Am J Phys Anthropol. 2003;122:251-8.

47. Ramanankirahina R, Joly M, Zimmermann E. Seasonal effects on sleeping site ecology in a nocturnal pair-living lemur (Avahi occidentalis). Int J Primatol. 2012:33:428-39.

48. Newey S, Thirgood SJ, Hudson PJ. Do parasite burdens in spring influence condition and fecundity of female mountain hares Lepus timidus? Wildl Biol. 2004;10:171-6.

49. Petter JJ, Albignac R, Rumpler Y. Faune de Madagascar: Mammifères lémuriens, primates prosimiens. 1st ed. Paris: ORSTOM, CNRS; 1977.

50. Irwin MT, Raharison J-L. A review of the endoparasites of the lemurs of Madagascar. Malagasy Nat. 2009;2:66-93.

51. R Core Team 2015. R: a language and environment for statistical computing. Vienna: R Foundation for Statistical Computing. http://www.R-proje ct.org. Accessed 16 Aug 2016.

52. Bates $D$, Mächler $M$, Bolker B, Walker S. Fitting linear mixed-effects models using Ime4. J Stat Softw. 2014;67:1-48.

53. Junge RE. Overview on the health and disease ecology of wild lemurs: conservation implications. In: Gould L, Sauther ML, editors. Lemurs: ecology and adaptations. New York: Springer; 2007. p. 423-40.

54. Junge RE, Louis EE. Medical evaluation of free-ranging primates in Betampona Reserve, Madagascar. Lemur News. 2002;7:23-5.

55. Chabaud A, Choquet M. Two nematode parasites of lemurs. Ann Parasitol Hum Comp. 1955;30:329.

56. Chabaud AG, Petter AJ, Golvan Y. Les nématodes parasites de lémuriens malgaches. III. Collection récoltée par M. et Mme Francis Petter. Ann Parasitol Hum Comp. 1961:36:113-26.

57. Kreis H. Beitrage zur Kenntnis parasitischer Nematoden. XII. Parasitische nematoden aus den Tropen. Rev Suisse Zool. 1945:52:551-96.
58. Chabaud AG, Brygoo ER, Petter AJ. Parasitic nematodes of Malagasy lemurs. VI. Description of six new species and general conclusions. Ann Parasitol Hum Comp. 1965:40:181-214.

59. Deblock S, Capron A. Bertiella lemuriformis nouveau Cestode Anoplocephalidae d'un lémurien de Madgascar (Lichanotus laniger Gmel.) Parassitologia. 1959;1:97-111.

60. Warren RD. Habitat use and support preference of two free-ranging saltatory lemurs (Lepilemur edwardsi and Avahi occidentalis). J Zool. 1997:241:325-41.

61. Loudon JE, Sauther ML. Verreaux's sifaka (Propithecus verreauxi) and ringtailed lemur (Lemur catta) endoparasitism at the Bezà Mahafaly Special Reserve. Madag Conserv Dev. 2013;8:21-8.

62. Springer A, Kappeler PM. Intestinal parasite communities of six sympatric lemur species at Kirindy Forest, Madagascar. Primate Biol. 2016;3:51.

63. Altizer S, Nunn CL, Lindenfors P. Do threatened hosts have fewer parasites? A comparative study in primates. J Anim Ecol. 2007;76:304-14.

64. Gompper ME, Williams ES. Parasite conservation and the black-footed ferret recovery program. Conserv Biol. 1998;12:730-2.

65. Yoder AD, Yang Z. Divergence dates for Malagasy lemurs estimated from multiple gene loci: geological and evolutionary context. Mol Ecol. 2004;13:757-73.

66. Poulin R. Macroecological patterns of species richness in parasite assemblages. Basic Appl Ecol. 2004;5:423-34.

67. Hugot JP. Primates and their pinworm parasites: the Cameron hypothesis revisited. Syst Biol. 1999;48:523-46.

68. Junge RE, Sauther ML. Overview on the health and disease ecology of wild lemurs: conservation implications. In: Gould L, Sauther M, editors. Lemurs: ecology and adaptation. New York: Springer; 2006. p. 423-40.

69. Raharivololona BM, Ganzhorn JU. Seasonal variations in gastrointestinal parasites excreted by the gray mouse lemur Microcebus murinus in Madagascar. Endanger Species Res. 2010;11:113-22.

70. Schad GA. The role of arrested development in the regulation of nematode populations. In: Esch GW, editor. Regulation of parasite populations. New York: Academic Press; 1977. p. 111-67.

71. Michel J. Arrested development of nematodes and some related phenomena. Adv Parasitol. 1974;12:279-366.

72. Eysker M. Some aspects of inhibited development of trichostrongylids in ruminants. Vet Parasitol. 1997;72:265-83.

73. Vitazkova SK, Wade SE. Effects of ecology on the gastrointestinal parasites of Alouatta pigra. Int J Primatol. 2007;28:1327-43.

74. Becker A-C, Rohen M, Epe C, Schnieder T. Prevalence of endoparasites in stray and fostered dogs and cats in Northern Germany. Parasitol Res. 2012;111:849-57.

75. Rakotoniaina JH, Kappeler PM, Ravoniarimbinina P, Pechouskova E, Hämäläinen AM, Grass J, Kirschbaum C, Kraus C. Does habitat disturbance affect stress, body condition and parasitism in two sympatric lemurs? Conserv Physiol. 2016. https://doi.org/10.1093/conphys/cow034.

76. Von Engelhard N, Kappeler PM, Heistermann M. Androgen levels and female social dominance in Lemur catta. Proc Biol Sci. 2000;267:1533-9.

77. Zohdy S, Gerber BD, Tecot S, Blanco MB, Winchester JM, Wright PC, Jernvall J. Teeth, sex, and testosterone: aging in the world's smallest primate. PLOS ONE. 2014;9:e109528.

Ready to submit your research? Choose BMC and benefit from

- fast, convenient online submission

- thorough peer review by experienced researchers in your field

- rapid publication on acceptance

- support for research data, including large and complex data types

- gold Open Access which fosters wider collaboration and increased citations

- maximum visibility for your research: over 100M website views per year

At $\mathrm{BMC}$, research is always in progress.

Learn more biomedcentral.com/submissions 